\title{
La lírica popular infantil en los cancioneros de la Segunda República
}

\author{
Folk Children's Lyrical Poetry in the songs \\ of the Second Republic
}

\author{
Cristina CAÑAMARES TORRIJOS y Ángel Luis LUJÁN ATIENZA \\ Universidad de Castilla-La Mancha \\ Cristina.Canamares@uclm.es / AngelLuis.Lujan@uclm.es \\ ORCID ID: 0000-0002-9494-4808 / ORCID ID: 0000-0003-0244-2358
}

\begin{abstract}
Children's folk lyrical poetry was used as RESUMEN: La lírica popular infantil fue utilizada a medium of instruction to remedy illiteracy in 1930s como medio de enseñanza para contrarrestar el and 1940s Spain. Two of the songbooks employed analfabetismo en la España de los años 30 y 40 were Canciones infantiles by Maria Rodrigo and gracias a que favorecen el acceso al texto. Dos de Elena Fortun and Poesía infantil recitable by Jose los cancioneros usados fueron Canciones infantiles Luis Sanchez Trincado and Rafael Olivares Figueroa. de María Rodrigo y Elena Fortún y Poesía infantil The compilation and fixing of this songbooks have a recitable de José Luis Sánchez Trincado y Rafael subversive intention, as they try to keep and Olivares Figueroa. La recopilación y fijación de emphasize the popular tone. The songs deal with dichos cancioneros tiene una intención subversiva, topics such as love, death, religion, among others. All pues intentan conservar y resaltar el tinte popular. this goes to show not only the editors' interest in Las canciones tocan temas como el amor, la muerte, keeping the popular tone but also the difficulties that la religión, entre otros. Todo ello muestra no solo el they faced. interés por conservar el tono popular de las antologías, sino las dificultades a las que se enfrentaron.
\end{abstract}

KeYwords: Second Republic, education, children PALABRAS-ClAVE: Segunda República, educación, lyrical poetry, songbooks, folklore lírica infantil, cancionero, folklore

No es necesario insistir en el esplendor que vivió la literatura española en los años 20 y 30 del pasado siglo. Gracias al contacto con las corrientes literarias europeas más innovadoras, al entusiasmo de los jóvenes escritores y al apoyo institucional para el fomento de la creación en las artes y el pensamiento, nuestras letras disfrutaron de una llamada «Edad de plata», fenómeno que afectó también a la literatura infantil y juvenil. En palabras de Pedro Cerrillo, fue:

[u]no de los periodos más interesantes jamás vivido en la literatura española: la «edad de plata» o segunda «edad de oro», en la que se unieron en talento de los veteranos escritores modernistas y noventayochistas, la madurez creadora de los novecentistas y el arrebatador empuje de los jóvenes poetas del «Grupo del 27», herederos de la mejor tradición literaria española, renovadores de la lírica popular y dignos representantes de las nuevas corrientes artísticas que aparecían, con más o menos éxito, en Europa. De ello también participó la LIJ (2013: 45). 
Para erradicar las altas tasas de analfabetismo que tenía España (superiores al $32 \%$ ), la Segunda República ideó un ambicioso proyecto educativo (vid. Cerrillo y Miaja, 2013,33-39) en el que se aunaban proyectos de cultura popular y programas de educación no formal - como los amparados por el Patronato de las Misiones Pedagógicas - , una decidida promoción del libro y la lectura, así como una profunda reforma del sistema educativo $\mathrm{y}$, especialmente, de la formación de los maestros, iniciativas que, lamentablemente, quedaron truncadas por la Guerra Civil y el triunfo de los sublevados.

Hubo también en aquellos años un decidido interés por llevar la poesía a la escuela, para acercarla a los niños y que pudieran disfrutarla. En España el movimiento krausista — que desembocó en la creación de la Institución Libre de Enseñanzadefendía, entre otras cosas, una pedagogía basada en aspectos comprensivos más que en memorísticos, lo que obligaba a poner en contacto al alumno con el objeto de conocimiento. Por ello, en el área de Lengua y Literatura sustituyeron el libro de texto por recopilaciones poéticas ${ }^{1}$ (populares y de autor) y defendieron la utilización de juegos y canciones infantiles como recurso educativo para ejercitar la memoria, la atención, la inteligencia, la mímesis y para introducir a los más jóvenes en la literatura (vid. Sánchez Ortiz, 2010: 21).

Muchos autores que destacaron en la Segunda República demostraron un gran interés por la tradición popular española y la dieron a conocer. Los ejemplos más sobresalientes son los de García Lorca — con el rescate del folclore andaluz y las canciones populares antiguas_-, y Rafael Alberti — con la imitación de los villancicos recogidos en los cancioneros medievales y renacentistas-. Autores como ellos incluyeron en sus textos composiciones del Cancionero Popular de Tradición Infantil (en adelante, CPI) o se las apropiaron como hipotextos de sus obras. Con esta iniciativa recuperaron y fijaron por escrito la riquísima lírica popular infantil de tradición popular, dignificándola y, muchas veces, utilizándola para iniciar a los niños en la lectura de la poesía, en un intento por partir de los conocimientos previos del niño, pues no hay que olvidar que:

[a]ntes de saber leer y escribir, los niños participan de muchas manifestaciones del folclore literario, formando parte de la cadena hablada que interviene en la recepción y, en ocasiones, en la transmisión de obras literarias de tradición oral, algunas de las cuales tienen a los propios niños como principales e, incluso, únicos destinatarios: cuentos maravillosos, nanas, juegos mímicos, oraciones, cuentos de nunca acabar, trabalenguas o adivinanzas (Cerrillo y Sánchez Ortiz, 2007: 18).

Algunas voces, como la de Gabriela Mistral, se alzaron para denunciar, ya en 1935, el escaso aprovechamiento que se hacía del folclore por parte de la escuela, llegando a afirmar incluso que la única poesía infantil válida era «la popular y propiamente el folklore» (Mistral, 1935: 145). No es de extrañar que en ese contexto proliferaran romanceros, antologías y colecciones de gran interés, entre las que podemos destacar las de uso escolar Lo que cantan los niños, de Fernando Llorca (1914), Canciones infantiles de María Rodrigo y Elena Fortún (1934) y Poesía infantil recitable de José Luis Sánchez Trincado y Rafael Olivares Figueroa (1935).

${ }^{1}$ El propósito del Patronato de las Misiones Pedagógicas no solo fue la creación de bibliotecas circulantes y de acciones culturales que llegaran a todos los rincones de España, sino también la promoción, selección y acceso a «obras escolares complementarias» que, en gran parte, sustituyeron en los centros educativos a las denostadas enciclopedias y gramáticas, y contribuyeron, a su vez, a la creación y fomento de los hábitos lectores de aquellos niños y jóvenes de los años 20 y 30. 
Analizaremos, por su representatividad y por el hecho de que manejan criterios muy contrastantes para la selección, dos de los cancioneros editados durante la Segunda República: Canciones infantiles de María Rodrigo y Elena Fortún (1934) y Poesía infantil recitable de José Luis Sánchez Trincado y Rafael Olivares Figueroa (1935). Ambos son reflejo del «decidido interés de las autoridades educativas [de la 2. ${ }^{a}$ República] por iniciar a los niños en la lectura de poesía mediante la recuperación y fijación escrita de la gran tradición española de poesía popular» (Cerrillo y Miaja, 2013: 38). La primera era una cuidada selección de canciones populares de tradición infantil que estaban vivas en la colectividad y que se difundían oralmente y, la segunda, una fantástica antología que incluía poesía popular (romances anónimos, adivinanzas o canciones escenificadas) y poemas de autores como Lorca o Alberti.

\section{DOS MODOS DE ACERCAR LA POESÍA A LOS NIÑOS}

Canciones infantiles, de María Rodrigo y Elena Fortún es una selección de treinta y cuatro «bellas canciones infantiles» (Fortún, 1934: 5) que mantenían su vigencia en los juegos infantiles. En el prólogo de la obra Elena Fortún admite que María Rodrigo las «encontró jugando al corro en Recoletos frente a la iglesia de San Pascual» (Fortún, 1934: 5) mientras que ella misma las «cantaba en el Jardín Botánico de Madrid y en las plazas de Oriente y de Santa Ana» (Fortún, 1934: 5).

Las antólogas clasifican las composiciones en ocho grupos (vid. Anexo I): Romances y romancillos de los siglos XVI y XVII; Romance de ciego; Viejas canciones; Viejas canciones infantiles; Canciones adaptadas del francés; Siglos XVII y XIX; Otras canciones e Invocación.

María Rodrigo y Elena Fortún ofrecieron la recopilación a las niñas para no perder este acervo que había pervivido, en algunos casos, durante siglos:

Para vosotras, niñas españolas y de la América latina, han sido reunidas estas canciones. Que ellas sirvan para haceros recordar las que hayáis olvidado, o modificar las que sabéis mal, y para enseñaros aquellas que no habéis aprendido todavía, pero que las lleváis en el corazón, como llevan los pájaros, que aún están en el nido, los trinos de todos los de su especie. (Fortún, 1934: 12)

En la recopilación y fijación escrita de estas canciones hay también una intención subversiva: la de recuperar y ofrecer a las futuras generaciones las auténticas composiciones pues «esta generación infantil y la que ahora tiene veinte años han sido educadas en conventos y han olvidado nuestra pícara Musa, que asustó a los reverendos y avergonzó a las buenas madres francesas» (Fortún, 1934: 6). Es decir, optan por las versiones más populares intentando dejar a un lado las torpes y falaces modificaciones realizadas por adultos empeñados en manipularlas con diversos propósitos. Por ejemplo, en La pastora se incorpora «de penitencia te echo/ que me des un besito» (Rodrigo y Fortún, 1934: 71) en lugar de «que reces un credito», opción que, quizá, era más del gusto de los adultos que no veían con buenos ojos la curiosa penitencia del padre Benito.

En cuanto a los contenidos de estas composiciones hemos de tener en cuenta que estas canciones no tienen su soporte en el significado sino en las formas, el ritmo, el sonido y, en definitiva, el juego. Por eso es muy común la aparición de incoherencias ${ }^{2}$ y

\footnotetext{
${ }^{2}$ Sirvan de ejemplo las siguientes canciones plagadas de sinsentidos: Ni tú, ni tú, ni tú; Muriéndose de risa; Carbonerita de Salamanca; La rana o, la conocidísima, Tengo una muñeca.
} 
frases sin sentido ${ }^{3}$, extravagancias léxicas y morfológicas ${ }^{4}$, juegos fónicos con elementos léxicos ${ }^{5}$, o que el tema no trascienda más allá de una anécdota baladí como, por ejemplo, un encuentro fortuito al recuperar un anillo caído dentro del agua en Quisiera ser tan alta como la luna; la exención que tienen las niñas bonitas de pagar el viaje en El barquero o las tareas cotidianas en La pastora.

Teniendo en cuenta que algunas composiciones son meros soportes de los juegos que acompañan, hay algunos temas que se repiten constantemente: los sentimentales (la muerte y, sobre todo el amor) y los religiosos. El tema de la muerte es el motivo central de algunas canciones como Mambrú se fue a la guerra y Elisa de Mambrú, y aparece en algunas composiciones de tema religioso como en El Martirio de Santa Catalina. También la muerte se torna en el triste final de algunas composiciones de tema amoroso como el Romance del amor y de la muerte o ¿Ha visto usted a mi marido...?, en los que se narra la pérdida del ser amado. En otros casos la muerte se torna castigo que un padre inflige a su hija al sentirse deshonrado. Este es el caso de Delgadina, encerrada por su padre en «una torre muy alta», sin comida ni bebida al confesarle que está enamorada. En otra canción, en Las niñas de Merino, la más pequeña de las tres hijas escapa de casa para verse con su galán «en un portal muy obscuro». Allí le promete: «Contigo me he de casar/ aunque me cueste la vida», últimos versos del poema que su padre escucha y parecen convocar la tragedia.

Las canciones de tema amoroso, como hemos visto en los ejemplos anteriores, muchas veces tienen un componente negativo. Casi siempre suelen referirse a amores truncados o irrealizables, bien por la muerte del amado o bien por unir lazos familiares a los enamorados como en El día de los torneos. En ocasiones las canciones son tristes lamentos por la desdicha de estas niñas cuyos padres «disponían a su antojo de la vida de sus hijas» (Fortún, 1934: 6) y las obligaban a entrar en conventos ${ }^{6}$ o concertaban matrimonios que las hacían desdichadas como en La viudita del conde de Cabra o en Me casó mi madre, en la que «el muchachito» la engañaba con otra mujer y le daba «palos y mala vida» (Rodrigo y Fortún, 1934: 29).

En otros casos, los menos, el amor se ve de forma positiva y las canciones expresan un deseo por enamorarse y casarse como en La viudita del conde Laurel. Esta parece ser una constante en las canciones que las niñas cantan mientras juegan girando en el corro.

Salvo alguna rara excepción como Arroyo claro en la que es el varón quien hace el ofrecimiento amoroso:

¡quién fuera cordón verde

de tu justillo,

para entrar en tu cuarto

y dormir contigo.

(Rodrigo y Fortún, 1934: 47)

\footnotetext{
${ }^{3}$ «Con el alsa piripi, / túmbamela, túmbamela, túmbamela, / con el alsa piripi, / túmbamela, túmbamela, y ya está». (Rodrigo y Fortún, 1934: 61).

4 «iCarabí, hurí, hurá!» (Rodrigo y Fortún, 1934: 73).

5 «En Salamanca tengo, / en Salamanca tengo, / ten, ten, ten, / tengo sembrado, / tengo sembrado, / azúcar y canela, / azúcar y canela, / pi, pi, pi, / pimienta y clavo, / pimienta y clavo». (Rodrigo y Fortún, 1934: 49).

${ }^{6}$ Este es el caso de la Monjita del monasterio (primera parte) que quiere casarse «con un mocito barbero» y de Monjita del monasterio (segunda parte) en cuyos versos finales la niña se lamenta: «Malhaya mis padres/ que no me casaron, / que para monjita/ yo no me he criado» (Rodrigo y Fortún, 1934: 19).
} 
En la mayoría de los casos son las féminas las que toman la iniciativa: en El patio de mi casa se reta a ese «tú» a que aproveche la ocasión pues:

que si tú no me quieres,

otro amante me querrá.

O, más directamente «que si tú no me quieres, otro amante tendré yo». Esta libertad se plasma en Los cuatro novios, canción en la que unas colegialas alardean de sus amores y en la composición titulada Consejos, en la que van rechazándose los hipotéticos pretendientes que pueden presentarse a una chica: un soldado, un estudiante, un sargento y un teniente. Le aconseja rechazarlos a todos menos al último:

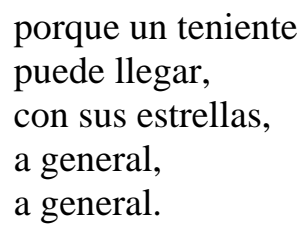

Todas las composiciones persiguen el triunfo del amor como se insinúa en Mayo, en la que se produce el encuentro entre el caballero y la Jardinera hermosa, o en El vestido nиevo, en la que asistimos al enfrentamiento de una pareja que riñen, quizá, por amores. En otras, en cambio, se produce un lamento por no haber alcanzado el amor como en Ramón del alma mía:

\author{
si te hubieras casado \\ cuando te lo dije yo \\ estarías ahora \\ sentadito en el balcón. \\ (Rodrigo y Fortún, 1934: 93)
}

Las composiciones de asunto religioso generalmente se refieren a un milagro como en San Antonio y los pajaritos o en El martirio de Santa Catalina. Otras como ; Que llueva! son meras peticiones de ayuda o auxilio como en este caso que se invoca a la Virgen de la Cueva para que llueva.

Por su parte, la obra de Sánchez Trincado y Olivares Figueroa tuvo un enorme éxito editorial pues enseguida se hizo una segunda edición y fue seleccionada, por orden ministerial de 5 de febrero de 1936, para uso en las escuelas. Su función pedagógica queda clara en las palabras introductorias que están dirigidas a los maestros y padres.

Los antólogos distinguen entre una poesía «superlativa», la de los grandes genios literarios, y otra «poesía menor», que, sin dejar de ser poesía auténtica, tiene un tono más humilde y sencillo: sería la practicada por mujeres, niños y el pueblo. Independientemente de lo que pueda haber de prejuicio de época en esta distinción, lo cierto es que los antólogos ponen de manifiesto el evidente lazo entre la poesía infantil y la popular, o incluso su identificación: «Lo natural, lo brotado espontáneamente del pueblo o de la infancia, ligeramente preparado, elaborado apenas por la técnica leve del poeta adulto» (Sánchez Trincado y Olivares Figueroa, 1935: IX).

Finalmente, los responsables de la selección dan una definición de poesía infantil como aquella «hecha para que los niños la digan como si fuese suya» (Sánchez Trincado y Olivares Figueroa, 1935: IX), es decir, sería poesía infantil toda aquella de la que se 
pueden apropiar los niños; y la forma más perfecta de apropiación es el recitado oral, de ahí que en el título aparezca el término «recitable». La antología, en consecuencia, acoge tanto poesía de autor como poesía popular; tanto poesía infantil en sentido estricto como poesía no pensada para ellos pero que los niños pueden hacer fácilmente suya.

Entre las composiciones cultas llama la atención la cantidad de poemas de autores contemporáneos (generación del 27), que, como hemos dicho, renovaron la tradición popular en sus composiciones. Ello da idea de la modernidad de la propuesta y lo informados que estaban los antólogos sobre el panorama poético contemporáneo: Alberti, García Lorca, Altolaguirre, Salinas, Ramón de Basterra, etc.

En cuanto a la poesía no de autor, los seleccionadores hacen una distinción curiosa entre composiciones «anónimas»y pertenecientes al «folklore», para diferenciar los poemas que provienen de la tradición culta, pero cuyo autor no se conoce, de los genuinamente populares. Por ejemplo, dan como «anónimos» todos los romances, considerándolos obras de autor, aunque desconocido. También dan como anónimas todas las composiciones recogidas de los cancioneros renacentistas, aunque sabemos que la mayoría de ellas pertenecen a la lírica popular, y reservan el marbete de folklóricas para todas las que han extraído de recopilaciones de folcloristas o lírica antigua como la de Cejador y Frauca, Rodríguez Marín o Machado Álvarez. Aunque en ocasiones consideran como autor al que en realidad es recopilador, como en la composición popular «Aquellas Sierras, Madre...», que atribuyen a Diego Pisador. O dan como anónima la canción «Gritos daba la morenica» (Sánchez Trincado y Olivares Figueroa, 1935, 82), de clara inspiración popular, simplemente porque está tomada de un cancionero musical del siglo XVI (el de Esteban Daca). En definitiva, la distinción entre anónima y popular viene establecida por el tipo de fuentes que utilizan los compiladores, sin que corresponda exactamente a la propia naturaleza de las composiciones.

La obra viene dividida en secciones; después de un «Umbral» de Pedro Salinas, tenemos los apartados: «Poemas de Mar, de Bosque y Montaña», «Canciones de juegos», «Érase una vez...», «Caprichos y adivinanzas», «Fabulario», «Gozos, oraciones y villancicos», «Corros y nanas», «Pregones y cantares», «Arca de animales», «Baladas y elegías», «Divertimentos», «Semblanzas» y «Musa pastoral». Aunque no se corresponden exactamente, estas secciones contienen prácticamente todos los géneros en lo que se puede dividir la poesía infantil: retahílas, canciones escenificadas (juegos), adivinanzas, oraciones, villancicos, nanas, canciones de corro, romances y pregones. Destacamos particularmente la aparición de este último género que no se suele tomar muy en cuenta en las recopilaciones de poesía infantil.

Entre las canciones de juegos tenemos el «Hola, Lirón, Lirón... ${ }^{7}$ (Sánchez Trincado y Olivares Figueroa, 1935: 17), «Sopla sopla el viento Norte», la conocida canción del trebolé (Sánchez Trincado y Olivares Figueroa, 1935: 18), una variante de «Al rabo, rabijar», cuyo primer verso es «Al regato de la sierra ${ }^{8} »$, el conocido «Dime, ovejita negra» (Sánchez Trincado y Olivares Figueroa, 1935: 19), y junto a estas populares se recogen canciones de juego cultas de Casona, Rogelio Buendía y García Lorca. Igual mezcla encontramos en las adivinanzas donde junto a las de García Lorca tenemos las genuinamente populares de la caña, las estrellas y el gallo. En cuanto a los

\footnotetext{
${ }^{7}$ Esta canción de juego aparece, como preliminar junto a la loa, en la obra del dramaturgo del siglo XVII Miguel Sánchez, «La guarda cuidadosa» (en Mesonero Romanos, 1857: 2). Véase también Frenk (2013: 46-47).

${ }^{8}$ Sobre este juego se puede ver Pelegrín (1998: 130). La variante por la que optan los autores («Al regato de la sierra») está tomada de la recopilación de Cejador y Frauca.
} 
caprichos, que parecerían equipararse a las retahílas, en realidad se trata de canciones y no se recoge ninguna genuinamente popular. El único anónimo que aparece:

Ten, amor, el arco quedo,

que soy niña y tengo miedo

(Sánchez Trincado y Olivares Figueroa, 1935: 39)

es en realidad una glosa culta de un estribillo popular.

Por lo que respecta a los villancicos los dos anónimos que se incluyen no son de carácter popular: «Villancico Franciscano» (de una colección de «Villancicos a San Francisco» de 1672) y la letrilla «Aquel Zagalito ${ }^{9} »$ (de «Rimas del Incógnito» del siglo XVII). A pesar del título de la sección no aparecen oraciones como tales aquí y tampoco los villancicos recogidos son desde luego conocidos.

De canciones de corro se incluye la popular «Arroyo claro» (Sánchez Trincado y Olivares Figueroa, 1935: 58), pero las nanas presentes en esta sección son todas cultas. En cuanto a los cantares (los pregones son todos cultos) tenemos cuatro piezas procedentes del folklore extraídas según los autores de las obras de Rodríguez Marín y Antonio Machado Álvarez: «Alborada» (Sánchez Trincado y Olivares Figueroa, 1935, 66), que conserva el lenguaje medieval, «Yo tiré un limón por alto» (Sánchez Trincado y Olivares Figueroa, 1935: 67), «Aquel pajarito, Madre» (Sánchez Trincado y Olivares Figueroa, 1935: 68), y «La voz de este niño mío» (Sánchez Trincado y Olivares Figueroa, 1935: 68).

En la sección de animales se selecciona solo un anónimo: «Dijo el gato ¡mau!» (Sánchez Trincado y Olivares Figueroa, 1935: 77), tomado de Cejador y Frauca. Y en la última sección, «La musa pastoril», tenemos, como anónimo, un cantar de lavandera: «Ribericas del río de Manzanares» (Sánchez Trincado y Olivares Figueroa, 1935: 107), tomado del Romancero General.

En cuanto a los romances, que ya hemos dicho que se dan todos como anónimos, se recogen: «Yo me levantara, madre» (Sánchez Trincado y Olivares Figueroa, 1935: 10), tomado del Cancionero de Amberes; «Guerra pregonan los Montes» (Sánchez Trincado y Olivares Figueroa, 1935: 13); «La infantina encantada» (Sánchez Trincado y Olivares Figueroa, 1935: 30), «El infante Arnaldos» (Sánchez Trincado y Olivares Figueroa, 1935: 33) y «El prisionero» (Sánchez Trincado y Olivares Figueroa, 1935: 85), tomados los tres de la recopilación de Menéndez Pidal, Flor nueva de romances viejos. Del tema popular de Delgadina se incluye una versión culta de José María Quiroga Pla, en lugar del romance original (Sánchez Trincado y Olivares Figueroa, 1935: 81-82). Por último, una composición de tipo villancico, «Galeritas de España» (Sánchez Trincado y Olivares Figueroa, 1935: 9), con una cabeza en seguidillas y el desarrollo estrófico en hexasílabos, tiene como fuente el Manuscrito 14.070 de la Biblioteca Nacional.

Como podemos comprobar los recopiladores han pretendido sobre todo llevar a los niños la gran tradición de la poesía culta seleccionando de entre las composiciones de autor las más apropiadas para el recitado infantil. Lo podemos ver en el predominio de las composiciones de autor sobre las genuinamente populares, autores que en la mayoría de los casos son contemporáneos de la selección, con un dominio claro de la generación del 27. Incluso cuando se eligen textos populares se hace con cierto prurito erudito, pues las fuentes que se citan son cancioneros musicales del siglo XVI, recopilaciones de

\footnotetext{
${ }^{9}$ La pieza proviene de un manuscrito de principios del siglo XVII editado por Foulché-Delbosc en Revue Hispanique, XXXVII, 1916.
} 
folkloristas (Cejador y Frauca, Rodríguez Marín, Machado Álvarez) e incluso un manuscrito de la Biblioteca Nacional, como acabamos de ver.

Los seleccionadores, en consecuencia, no han optado por las composiciones más populares, en el sentido de más difundidas y conocidas. De hecho, si comparamos los dos volúmenes de poesía infantil estudiados, comprobamos que solo coinciden en una composición: «Arroyo claro». La diversa intención de ambas compilaciones es evidente: en la de Fortún se trata de reforzar y preservar un canon ya bien establecido de base genuinamente popular; mientras que la de Sánchez Trincado pretende abrir el canon de la poesía infantil por una parte incorporando la poesía culta contemporánea y clásica apropiada para los niños y por otra parte explorando nuevas vías, apenas transitadas, en la tradición genuinamente popular.

\section{RASGOS O ELEMENTOS PROPIOS DE LA POESÍA POPULAR}

La lírica popular de tradición infantil ofrece una serie de elementos literarios, que estructural y formalmente la caracterizan e identifican. El CPI ha sido objeto de distintas propuestas de clasificación, entre las que destacan las de Ana Pelegrín (1982, 36-38), Rodríguez Almodóvar (2009: 16-23), Pascuala Morote (2010: 66) y Pedro Cerrillo (1994: 37-54). Esta última, elegida para nuestra investigación, atiende al criterio de «tipo» establecido por Stith Thompson y, en palabras de su autor, cada grupo - de los que a continuación se detallan- lo constituyen composiciones que tienen existencia independiente respecto a los demás, porque se usan en contextos diferentes y con finalidad distinta (Cerrillo, 1994: 50). Esta propuesta de clasificación diferencia las composiciones del CPI en siete tipos: nanas o canciones de cuna, juegos mímicos, canciones escenificadas, oraciones, fórmulas para echar a suertes y burlas y trabalenguas.

En el caso de Canciones infantiles de María Rodrigo y Elena Fortún, por tratarse de canciones que utilizaban las recopiladoras para jugar en su infancia, la mayoría de las composiciones pertenecen a la categoría «canciones escenificadas». Esta amplia presencia tal vez se deba al hecho de que en la mayoría de los casos las antólogas las seleccionaron porque servían de acompañamiento a sus juegos infantiles, especialmente al corro y las filas. En la recopilación de Sánchez Trincado, tenemos, sin embargo, como hemos visto, diversidad de géneros y aunque el número de recopilaciones folclóricas es menor que el de poemas cultos, sin embargo, es evidente que el criterio de selección de estos últimos responde a que contienen elementos estilísticos propios de la poesía infantil y popular.

Estas canciones infantiles reflejan los rasgos más destacados de este tipo de canciones populares infantiles: las indicaciones hacia la gestualidad, la insistente rima consonante aguda, la importancia de los valores sonoros (sobre todo la onomatopeya), así como las repeticiones idénticas de versos y la presencia de estructuras de corte repetitivo logradas, casi siempre, mediante la enumeración de elementos, el encadenamiento de unidades o por estructuras binarias, en la que dos o más voces desarrollan la acción por medio del diálogo o la utilización de preguntas y respuestas. Veamos, a modo de ejemplo, la canción Carbonerita de Salamanca:

En Salamanca tengo, en Salamanca tengo, ten, ten, ten, tengo sembrado, tengo sembrado, azúcar y canela, 
azúcar y canela,

pi, pi, pi,

pimienta y clavo,

pimienta y clavo.

(Rodrigo y Fortún, 1934: 49)

En el caso de Sánchez Trincado estos rasgos se ven claramente en «Al regato de la sierra», que ya hemos indicado que es una variante de la canción de juego «Al rabo rabijar»:

Al regato de la sierra,

donde el lobo fue a cazar.

Si cazó o no cazó,

el pastor se lo perdió

- ¿Periquillo?

— ¿Qué manda mi amo?

- ¿Cómo está el lobo?

- Se durmió sentado.

-Tírale de la oreja...

(Sánchez Trincado y Olivares Figueroa, 1935: 18)

Igualmente, el uso de diminutivos es un rasgo claro del CPI que aparece de forma insistente: monjita, mocito, Delgadina, pajaritos, carbonerita, camisita, Periquito, perrito, rebañito, quesitos, golositos, rabito, besito, manguito, viudita. A modo de ejemplo citaremos un fragmento de Monjita de monasterio (primera parte):
Me empezaron a quitar,
me empezaron a quitar,
los adornos de mi cuerpo,
los adornos de mi cuerpo,
pulseritas de mis manos
pulseritas de mis manos,
anillitos de mis dedos,
anillitos de mis dedos.
(Rodrigo y Fortún, 1934: 17)

Comprobamos en el ejemplo que el uso de los diminutivos obedece a un intento por destacar la fragilidad de la niña y por reflejar un claro tono afectivo y cercano.

Lo mismo ocurre en las composiciones recogidas por Sánchez Trincado, como el uso del diminutivo del nombre del niño en la canción de juego que hemos visto (Periquillo), la expresión «pobrecito jilguerito» (Sánchez Trincado y Olivares Figueroa, 1935: 16) en otro juego para subrayar igualmente la indefensión del pajarillo ante el temporal de frío que se avecina, frente al cual el niño-jilguero debe esconder la cabeza entre los brazos para protegerse; o en el juego de la «ovejita negra» para conseguir una mayor identificación entre el animal y el niño. Los autores cultos recogen este rasgo porque lo ven característico de la poesía popular infantil. Así una canción de juego ideada por uno de los recopiladores, Olivares Figueroa, se titula «El galapaguito» (Sánchez Trincado y Olivares Figueroa, 1935: 18) o la de Rogelio Buendía, «Pirulito» (Sánchez Trincado y Olivares Figueroa, 1935: 19), que es en realidad una variante de autor del conocido juego «Antón Pirulero». 
Otro de los recursos propios de la poesía popular, en general, y del CPI, en particular, que se utilizan insistentemente es la repetición de elementos para conseguir que la composición tenga un ritmo más ágil y para que pueda identificarse e, incluso, memorizarse más fácilmente. Este uso de estructuras de corte repetitivo provoca la aparición de estribillos, paralelismos y estructuras enumerativas como podemos apreciar en composiciones tan conocidas como La Tarara o La rana.

Del mismo modo, se incluyen estribillos que se construyen por repetición de palabras con exclusivo valor sonoro, muy cercano a la jitajánfora, tal y como sucede en Me casó mi madre o en Quisiera ser tan alta como la luna. En este sentido en Carbonerita de Salamanca se repite la sílaba inicial de la primera palabra del verso siguiente: «ten, ten, ten, [...] pi, pi, pi, [...], la, la, la [...] de, de, de». Veamos cómo se da gran importancia a los valores sonoros en Muriéndose de risa:

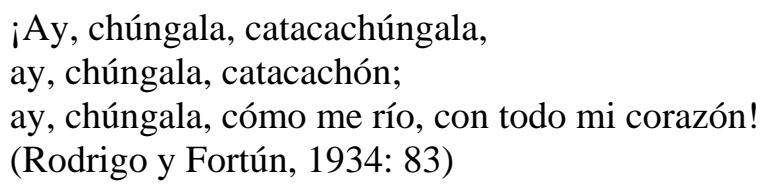

Esta técnica aparece poco usada en la recopilación de Sánchez Trincado; se da claramente en «Dijo el gato: ¡Mau!» (Sánchez Trincado y Olivares Figueroa, 1935: 77), que aparece como anónima, aunque su factura, entre otras cosas por este rasgo que estamos estudiando, es popular, pues utiliza como estribillo una serie de onomatopeyas:

ni gavau, ni gavuz,

polea polau,

ñiriñau, ñiriñau,

ñau, ñau, ñau, ñau!

Practica esta técnica, por ejemplo, Rafael Alberti en el conocido «Don Diego sin don», recogido aquí (Sánchez Trincado y Olivares Figueroa, 1935: 40).

En otras ocasiones, nos encontramos estribillos que resultan de la repetición regular de uno o más versos. Es el caso de Monjita del monasterio I, ¿Ha visto usted a mi marido...?, Me casó mi madre o la insistente repetición del verso «dice la abadesa» en Monjita del monasterio II. Esto es corriente también en las composiciones de la selección de Sánchez Trincado tanto en las folclóricas como en las de autor y se da especialmente en las secciones de los villancicos, que en su mayoría son en realidad letrillas o villancicos en el sentido renacentista (de Góngora y Lope de Vega, sobre todo) y de las canciones de corro, aunque no faltan de manera llamativa estribillos más conceptuales, propios de la vanguardia artística, poco comprensibles para los niños:

Yo y mi sombra, ángulo recto.

Yo y mi sombra, libro abierto.

(«Las barcas de dos en dos», de Manuel Altolaguirre [Sánchez Trincado y Olivares Figueroa, 1935: 6])

En lo relativo a la versificación, en la recopilación de Fortún, generalmente las composiciones utilizan el hexasílabo y octosílabo, a excepción de las canciones adaptadas al ritmo francés, que usan el verso de siete y nueve sílabas. Estas últimas, en palabras de Elena Fortún «son también graciosas y lindas, pero siempre un poco ñoñas y no 
enteramente acordes con nuestro espíritu» (Fortún, 1934: 8). Algunas canciones utilizan versos de diferentes medidas como: Carbonerita de Salamanca, Arroyo claro, Quisiera ser tan alta como la luna o San Antonio y los pajaritos.

En el caso de Sánchez Trincado dominan los versos cortos también (hexasílabo y octosílabo), pero al dar cabida a composiciones cultas la diversidad métrica es mayor, y aparece el endecasílabo e incluso el alejandrino, en una versión de «Caperucita Roja» en verso a cargo de Gabriela Mistral (Sánchez Trincado y Olivares Figueroa, 1935: 28-29), si bien es verdad que en las composiciones de corte popular la métrica se ajusta a las características del género.

Las estrofas son, en Rodrigo y Fortún, en su mayoría agrupaciones populares como la cuarteta, la redondilla y el romance. En Sánchez Trincado encontramos estos metros y otros muchos, como acabamos de indicar, debido a la mayor variedad métrica; junto a cuartetas, redondillas y romances, se da también el tipo villancico de la poesía popular, con una cabeza, el desarrollo estrófico y retorno a la cabeza, como el ejemplo claro de «Gritos daba la morenica» (Sánchez Trincado y Olivares Figueroa, 1935: 82). También se da cabida a la «copla», propia del folclore sobre todo andaluz, consistente en una sola cuarteta asonantada en los pares:

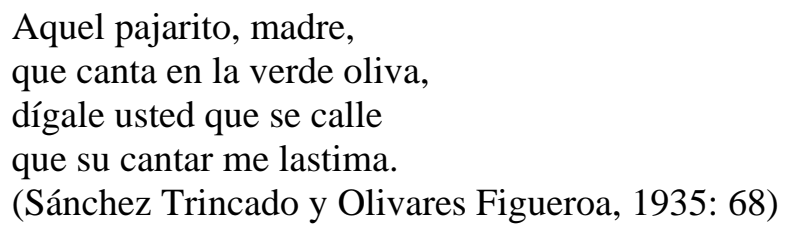

En el caso curioso de una traducción de Rimbaud, «Los boquiabiertos» [corresponde al poema «Les effarés»] (Sánchez Trincado y Olivares Figueroa, 1935: 100), se utiliza una variante de la sextilla manriqueña pero con versos de 9 y 5 sílabas y de rima asonante.

Incluso se da un caso sorprendente de irregularidad métrica, propio de la poesía verdaderamente popular, como es la canción «Alborada», que mezcla versos de 5, 6 y 7 sílabas:

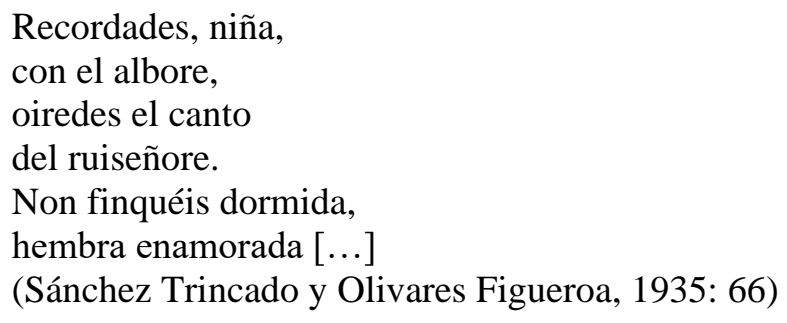

A la complejidad métrica hay que añadir la complejidad lingüística, ya que los antólogos han respetado el original medieval, incomprensible para los niños.

En todas estas composiciones abundan otros recursos propios del CPI como la inclusión de fórmulas de apertura y cierre, el corte repetitivo, la enumeración, el encadenamiento y la repetición de palabras, versos y sonidos. Por este motivo es común la presencia de epanadiplosis como, por ejemplo, en La muñeca:

Dos y dos son cuatro, cuatro y dos son seis seis y dos son ocho 
y ocho dieciséis.

(Rodrigo y Fortún, 1934: 57)

Y la aparición de estructuras binarias que se establecen en El día de los torneos; Delgadina o en el Romance del amor y de la muerte, por ejemplo.

Este uso constante de estructuras de corte repetitivo como las ya citadas provoca la aparición de estribillos y de paralelismos. Veamos algunos estribillos de Delgadina:

—Quítate de ahí, Delgadina, que eres una descastada; si mi padre, el rey, te viera, la cabeza te cortara. (Rodrigo y Fortún, 1934: 23)

O en el siguiente fragmento:

Delgadina se quitó, muy triste y desconsolada; luego se volvió a asomar a aquella misma ventana. (Rodrigo y Fortún, 1934: 23)

También es común el uso de la anáfora y del paralelismo sintáctico. A modo de ejemplo podemos citar una anáfora de Monjita del monasterio I: «Si voy a la torre [...] Si bajo a la huerta [...] Si gasto zapato» o el bellísimo paralelismo del Romance del amor y de la muerte:

Los brazos que te abrazaban

a la tierra se los di;

la boca que te besaba

los gusanos dieron fin.

(Rodrigo y Fortún, 1934: 25)

En Sánchez Trincado encontramos, según se ha visto, la típica estructura de la canción popular, basada en la repetición de un motivo con su correspondiente desarrollo:

Alta estaba la peña:

nace la malva en ella.

Alta estaba la peña,

riberas del río,

nace la malva en ella

y el trébol florido.

(Sánchez Trincado y Olivares Figueroa, 1935: 7)

O la más típica, estudiada por Margit Frenk (2006: 389-412), que consiste en una cabeza, el desarrollo y vuelta a la cabeza:

Gritos daba la morenica,

so el olivar,

que las ramas hacen temblar. 
La niña, cuerpo garrido, morenica, cuerpo garrido, llevaba su muerto amigo, so el olivar, que las ramas hacen temblar.

(Sánchez Trincado y Olivares Figueroa, 1935: 82)

Como comprobamos, no se trata del tipo de repeticiones más típicas de las composiciones infantiles, pues, según venimos diciendo, los seleccionadores han escogido gran parte de piezas del folklore del repertorio no propiamente infantil, lo cual afecta no solo a la forma, sino también a los temas, pues es fácil ver que el último poema citado es difícil que conecte con los niños. Sin embargo, hay que reconocer que la selección que han hecho de poemas de autor sí se rige por todos los principios formales y temáticos reconocidos de la poesía infantil que hemos ido desglosando. Baste este ejemplo de Gabriela Mistral en que encontramos repeticiones paralelísticas y anafóricas, con anadiplosis, juego de preguntas y respuestas, recolección final de los elementos nombrados en el poema e implicación del interlocutor en las acciones del canto y el tema es típicamente infantil:

\author{
¿En dónde haremos la ronda? \\ ¿La haremos a orilla del mar? \\ El mar danzará con mil olas, \\ haciendo una trenza de azahar. \\ ¿La haremos al pie de los montes? \\ El monte nos va a contestar: \\ ¡Será cual si todas quisiesen \\ las piedras del mundo cantar! \\ ¿La haremos mejor en el bosque? \\ Él va voz y voz a mezclar, \\ y cantos de niños y aves \\ se irán en el viento a besar. \\ ¡Haremos la ronda infinita: \\ la iremos al bosque a trenzar, \\ la haremos al pie de los montes \\ y en todas las playas del mar! \\ (Sánchez Trincado y Olivares Figueroa, 1935: 62)
}

La tradición popular, infantil o no, vive de repeticiones pero también de cambios y modificaciones que van dando vida a las canciones en su paso de generación en generación: «Porque ello es corriente y hacedero, lo mismo en las canciones infantiles que en las del pueblo, que pone, quita, aumenta y disminuye, modifica y da actualidad, haciendo de dos canciones una, intercalando versos, o suprimiendo los que no entiende o no le parecen necesarios» (Fortún, 1934: 8). Veamos, a modo de ejemplo el magnífico romance El amor y la muerte que las niñas, sabiamente, han aplicado a las desgracias reales. Esas niñas añadían cuatro primeros versos que, a modo de fórmula de inicio, utilizaban para entrar en materia. A la muerte de Fernando VII el inicio del romance decía así: 
De los árboles frutales

me gusta la pera fina,

y de las reinas de España

me gusta María Cristina. (apud Fortún, 1934: 9)

Cuando adaptaron el romance a la muerte de la reina Mercedes, las niñas cantaban:

De los árboles frutales,

me gusta el melocotón,

y de los reyes de España,

Alfonsito de Borbón. (apud Fortún, 1934: 9)

Elena Fortún se refiere a que el romance El amor y la muerte había quedado casi olvidado en aquellos años treinta pero no así «la belleza de la melodía, y con ella, y sirviendo de patrón esos cuatro versos postizos» (Fortún, 1934: 10), que continuaron readaptándose para aludir al jefe del Estado:

De los árboles frutales

me gusta la zarzamora,

y de los republicanos,

me gusta Alcalá Zamora.

(apud Fortún, 1934: 10)

«De aquí el valor de estas canciones, nacidas no se sabe dónde, que han rodado de boca en boca, puliéndose, gastando sus aristas, adaptándose a los tiempos, adquiriendo nuevos reflejos, llegando a nosotros como piedras preciosas, imposibles de imitar con bisutería» (Fortún, 1934: 8).

En el caso de Sánchez Trincado no se produce ningún cambio de este tipo. Como hemos visto se trata de una selección más «purista» y erudita, hasta el punto de que se dan las fuentes exactas de cada una de las composiciones. Ello hace que, como ya hemos anotado, se reproduzca una versión del conocido juego «Al rabo rabijar» con un primer verso cambiado: «Al regato de la sierra».

\section{CONCLUSIONES}

Hemos comprobado que las composiciones incluidas en el cancionero de Fortún, en su mayoría, conocidas previamente por el niño y que forman parte del CPI, favorecen el acceso al texto, ya que el lector como receptor del mismo «comprobará la eficacia de su intertexto, es decir advertirá los saberes que es capaz de activar extrayéndolos de su competencia literaria y de su experiencia lectora» (Mendoza, 2001: 58).

Estas referencias a composiciones de tradición infantil activan el intertexto lector de manera que la lectura de los textos remite a conocimientos literarios previos que el lector ya tiene y que forman parte de su patrimonio cultural por lo que para sus lectores estos textos literarios se perciben como algo cercano y, en ocasiones, familiar.

No podemos olvidar que estos juegos intertextuales servían para empatizar y conectar con los niños, que reconocían esas composiciones y activaban su experiencia lectora, porque «el intertexto del lector reconoce las conexiones que se dan entre obras, a través de la activación de los conocimientos y de la experiencia de recepción que posee el lector» (Mendoza 2001: 28). 
En el caso de la recopilación de Sánchez Trincado los responsables apuestan por la ampliación del canon de la tradición popular infantil y por la creación de un canon infantil procedente de la tradición culta; una doble vía que tiene más que ver con la sorpresa y la novedad que con el reconocimiento de textos anteriores por parte del niño, y por eso su propuesta es más arriesgada hasta el punto que hemos visto que se incluyen composiciones en ocasiones de difícil comprensión por parte del niño, por estar alejadas de su universo de intereses. No hay que descartar, entre los criterios de selección, cierto sesgo ideológico, pues en la sección «Érase una vez...», compuesta casi exclusivamente por romances narrativos, se incluye el romance de García Lorca al general Torrijos, claro referente del imaginario republicano; o en el hecho de que no aparezcan genuinas oraciones populares en el apartado que precisamente se titula así.

También es verdad que entre las composiciones cultas seleccionadas el niño encontrará resonancias de las características formales a las que está acostumbrado en sus cantos y juegos, e incluso personajes familiares como Blanca Nieves, Caperucita, Delgadina, etc.

En las composiciones analizadas observamos la reiteración de elementos tomados del CPI como: la utilización de fórmulas de apertura y cierre, de juego o sorteo, así como algunas exclusivas de determinadas composiciones. También hemos observado una insistente utilización del diminutivo, así como de palabras con valores sonoros muy pronunciados y un frecuente uso de estructuras de corte repetitivo, bien por enumeración o encadenamiento de elementos o por la reiteración idéntica de versos que provoca la aparición de estribillos, paralelismos y estructuras binarias.

En lo referente a las formas, apreciamos claridad y sencillez (léxica y sintáctica) en la exposición de las acciones, el ritmo es muy vivo y ágil y, en el caso concreto de la poesía infantil, su métrica se caracteriza por las siguientes constantes: preferencia por el verso de arte menor (sobre todo el hexasílabo y octosílabo), rimas reguladas (siendo más frecuente la asonante que la consonante, la alterna que la gemela o que la abrazada y la grave que la aguda) y estróficamente son más frecuentes — por este orden - la cuarteta, el pareado, la seguidilla simple, la redondilla y el romance y sus variantes de romancillo y de romance endecha. Hay que añadir que en la selección de Sánchez Trincado encontramos estas formas predominantes junto a otras más irregulares y más propias del folklore de tradición oral. 


\section{BIBLIOGRAFÍA}

CERRILlo, Pedro C. (1994): Lírica popular española de tradición infantil (Tesis doctoral. Universidad Autónoma de Madrid, 1986), I y II, Cuenca, Ediciones de la Universidad de Castilla La Mancha.

CERriLlo, Pedro C. (2013): «La literatura infantil y juvenil en la Segunda República. El primer impulso en España», en La LIJ española en el exilio mexicano, P. C. Cerrillo y M. ${ }^{\text {a }}$ T. Miaja (coord.), México, El Colegio de México, pp. 41-49.

Cerrillo, Pedro C. y MiAJA, M. ${ }^{a}$ Teresa (2013): «Literatura y educación. El final de un gran proyecto educativo», en La LIJ española en el exilio mexicano, P.C. Cerrillo y M. ${ }^{a}$ T. Miaja (coord.), México, El Colegio de México, pp. 27-39.

Cerrillo, Pedro C. y SÁnChEZ, César (2007): «Lo literario y lo infantil: concepto y caracterización de la Literatura Infantil», en La formación de mediadores para la promoción de la lectura, P.C. Cerrillo y S. Yubero (coord.), Cuenca, Ediciones de la UCLM y CEPLI, pp. 17-25.

DíAZ RoIG, Mercedes y MIAJA, M. ${ }^{\mathrm{a}}$ Teresa (2010): Naranja dulce, limón partido. Antología de la lírica infantil mexicana, México, El colegio de México.

FortúN, Elena (1934): «Prólogo», en Canciones infantiles, M. Rodrigo y E. Fortún, Madrid, Aguilar, pp. 5-12.

FRENK, Margit (1990): Corpus de la antigua lírica popular hispánica (siglos XV a XVII), Madrid, Castalia.

Frenk, Margit (2006): Poesía popular hispánica. 44 estudios, México, Fondo de Cultura Económica.

FRENK, Margit (2013): «Rimas para juegos infantiles en el antiguo cancionero popular», en Presencia del cancionero infantil en la lírica hispánica (Homenaje a Margit Frenk), P. C. Cerrillo y C. Sánchez (coord.), Cuenca, Universidad de Castilla-La Mancha, pp. 41-58. DOI: https://doi.org/10.18239/ocnos_2013.09.01

GARCÍA LORCA, Federico (2005): Obras completas, I, Barcelona, RBA.

GonZALO, Ángel J. y ARAQue, E. (2001): «Juegos infantiles del Siglo de Oro en la tradición folclórica moderna», en Lyra minima oral. Los géneros breves de la literatura tradicional, C. Alvar, C. Castillo, M. Masera y J. M. Pedrosa (coord.), Alcalá de Henares, Universidad de Alcalá, pp. 209-219.

MendozA, Antonio (2001): El intertexto lector. El espacio de encuentro en las aportaciones del texto con las del lector, Cuenca, Edicines de la UCLM.

Mesonero Romanos, Ramón de (1857): Dramáticos contemporáneos a Lope de Vega. Tomo primero, Madrid, Rivadeneyra.

Mistral, Gabriela (1935): «El folclore de los niños», Revista de Pedagogía, 160, pp. 145-152.

Morote, Pascuala (2010): Aproximación a la literatura oral. La leyenda entre el mito, el cuento, la fantasía y las creencias, Catarroja, Periféir Edicions.

PELEGRín, Ana (1982): «Poesía infantil de tradición oral», en Literatura Infantil, Madrid, Papeles de Acción Educativa, pp. 36-38.

PElegrín, Ana (1998): Repertorio de antiguos juegos infantiles, Madrid, CSIC.

Rodríguez Almodóvar, Antonio (2009): Del hueso de una aceituna. Nuevas aproximaciones a la literatura oral, Barcelona, Octaedro. 
RODRIGO, María y FORTúN, Elena (1934): Canciones infantiles, Madrid. Aguilar.

SÁnchez ORTIZ, César (2010): Cancionero Popular Infantil. Del texto oral al texto escrito. Estudio literario y aplicaciones didácticas, Tesis Doctoral. Universidad de Castilla La Mancha.

SÁnchez trincado, José Luis y Olivares Figueroa, Rafael (1935): Poesía infantil recitable, Madrid, Aguilar.

\section{ANEXO I: CORPUS DE ESTUDIO}

Índice de Canciones infantiles de María Rodrigo y Elena Fortún (1934).

Prólogo

Romances y romancillos de los siglos XVI y XVII

Monjita del Monasterio (primera parte)

Monjita del Monasterio (segunda parte)

El día de los torneos

Delgadina

Romance del amor y de la muerte

¿Ha visto usted a mi marido?

Me casó mi madre

Romance de ciego

San Antonio y los pajaritos

San Antonio y los pajaritos (versión que cantan los ciegos)

Viejas canciones

Quisiera ser tan alta como la luna

El barquero

Arroyo claro

Carbonerita de Salamanca

Viejas canciones infantiles

La rana

La muñeca

El patio de mi casa

Ni tú, ni tú, ni tú (canción asturiana)

Canciones adaptadas del francés

Mambrú se fué [sic] a la guerra

La pastora

Elisa de Mambrú

El martirio de Santa Catalina

Siglos XVII y XIX

Las niñas de Merino

Muriéndose de risa

La tarara

Los cuatro novios 
Consejos

El vestido nuevo

Ramón del alma mía

Las ovejuelas

\section{Otras canciones}

Mayo

La viudita del conde de Cabra

La viudita del conde Laurel

El caballo trotón

\section{Invocación}

¡Que llueva!

Fecha de recepción: 24 de abril de 2019

Fecha de aceptación: 3 de septiembre de 2019

$$
\text { i }
$$

